\title{
Liquid Air in Mine Rescue Apparatus.
}

THE Mines Rescue Apparatus Research Committee which was appointed by the Advisory Council for Scientific and Industrial Research to inquire into the types of breathing apparatus used in coal mines, and to determine experimentally the advantages, limitations, and defects of the several types, has recently presented its third and final Report. ${ }^{1}$ In the first report, attention was directed to certain serious defects in rescue apparatus, and to the training of rescue brigades ; and the lines along which improvement in design was necessary were indicated. In the second report, methods of testing compressed oxygen apparatus were proposed and descriptions of new and improved appliances were given. The third report deals principally with the use of liquid air and liquid oxygen in mine rescue apparatus, and will prove of interest not only to mining engineers but also to all who have occasion to use liquid air and oxygen.

The report includes, in addition to a detailed description of the new Brown-Mills aerophor rescue apparatus, an exhaustive treatment of the problem of the construction of vacuum storage vessels or containers for liquid air.

Liquid air was first used for mine rescue work in an apparatus known as "Aerolith," designed by an Austrian engineer, Herr Lüss, in Igo6. This apparatus, which was not provided with a purifier or regenerator for absorbing the carbon dioxide in the exhaled air, failed to supply an adequate amount of air to the wearer when a heavy task was being performed, and consequently its use was strictly limited. In I9Io Col. Blackett invented a regenerative liquid-air apparatus bearing the name of "aerophor" ; and it is this type of appliance in a modified and much improved form that has been installed recently in the Northumberland and Durham rescue stations.

The mode of action of the Brown-Mills aerophor, which is the most efficient and trustworthy of this type, will readily be understood by reference to Fig.'I, which is reproduced from the Report. It consists essentially of a "pack" $\mathrm{P}$ or liquid-air container, a regenerator or purifier $\mathrm{Q}$, a breathing-bag $\mathrm{M}$, and the necessary metallic and flexible tubes for conveying the gas from the " pack" to the bag and mouthpiece, and the exhaled air from the mouthpiece to the purifier. Liquid air is poured into the pack through a single central opening, and is absorbed by the calcined asbestos wool WW which is packed tightly in a perforated nickel silver case. The air space $C$ which surrounds this case serves to distribute the liquid during the process of charging, and to collect the evaporated air. The latter passes through a pipe $G$ into the space $\mathrm{E}$, which is loosely packed with asbestos. From the upper side of $\mathrm{E}$ the gas flows into a metal warming-pipe $H$, and thence through the tubular collar A to the breathing-bag. During inhalation, air is drawn both from the bag and the purifier through the valve $V_{1}$. The exhaled air passes through the valve $V_{2}$ to the purifier $Q$, where the carbon dioxide is removed by caustic soda, and thence through valves $V_{3}$ and $V_{1}$ back to the mouthpiece. The space $E$, in

1 Department of Scientific and Industrial Research: Advisory Council. Third and Final Report of the Mine Rescue Apparatus Research Committee. Pp. vi +32 . (London: H.M. Stationery Office, I924.) Is. net. addition to serving as an outlet for the evaporated air, impedes and to a limited degree regulates the flow of heat into the interior of the pack, and consequently controls the rate of evaporation. Immediately after charging the pack, the volume of cold air circulating in E, owing to the low specific heat of the liquid air, is very considerable, and consequently its insulating effect is a maximum. This results, at this stage, in a reduction in the amount of heat entering the inner chamber of the pack, and in a tendency to effect a diminution in the ebullition of gas, while towards the

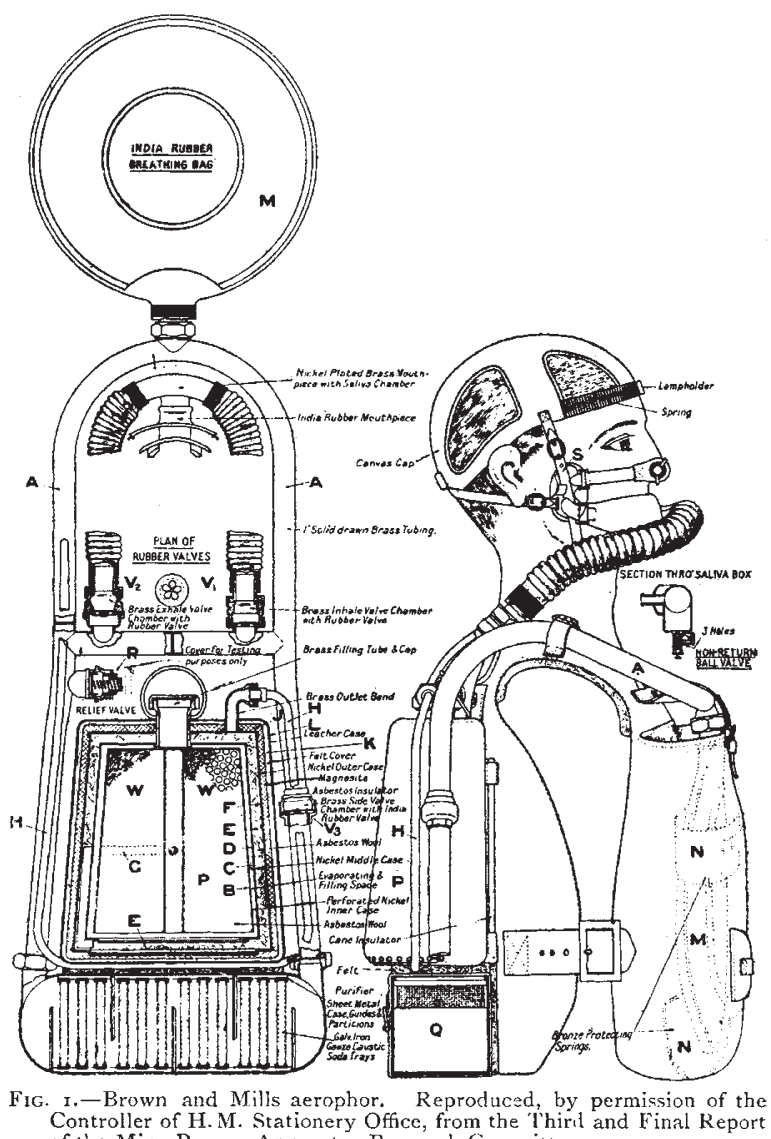
of the Mine Rescue Apparatus Research Committee.

end of a "run," when the evaporation is flagging, it is stimulated by an increase in the amount of heat across that space. In spite of this automatic means of regulation the discharge is variable, being approximately 30 litres per minute just after charging, and falling off to 8 litres per minute at the end of the two hours' period. An important feature of the appliance is the valve $V_{3}$, which prevents the excess of air delivered from the pack during the first part of a run flowing in a reversed direction through the purifier, and thereby rendering the caustic soda comparatively inert by cooling. The pressure of the air in the breathing circuit is controlled by the relief valve $R$, which is set to operate at a pressure of about I $8 \mathrm{lb}$. per square foot. The total weight of the apparatus, including the approved charge of $5 \frac{1}{2} \mathrm{lb}$. of liquid air and $2 \mathrm{lb}$. of absorbent, is about $40 \mathrm{lb}$. 
The chief advantage claimed for the aerophor, and f flasks, each containing 5o lb. of air, were carried in a one that is recognised by the Research Committee, heavy motor ambulance for a distance of $7 \cdot 6$ miles

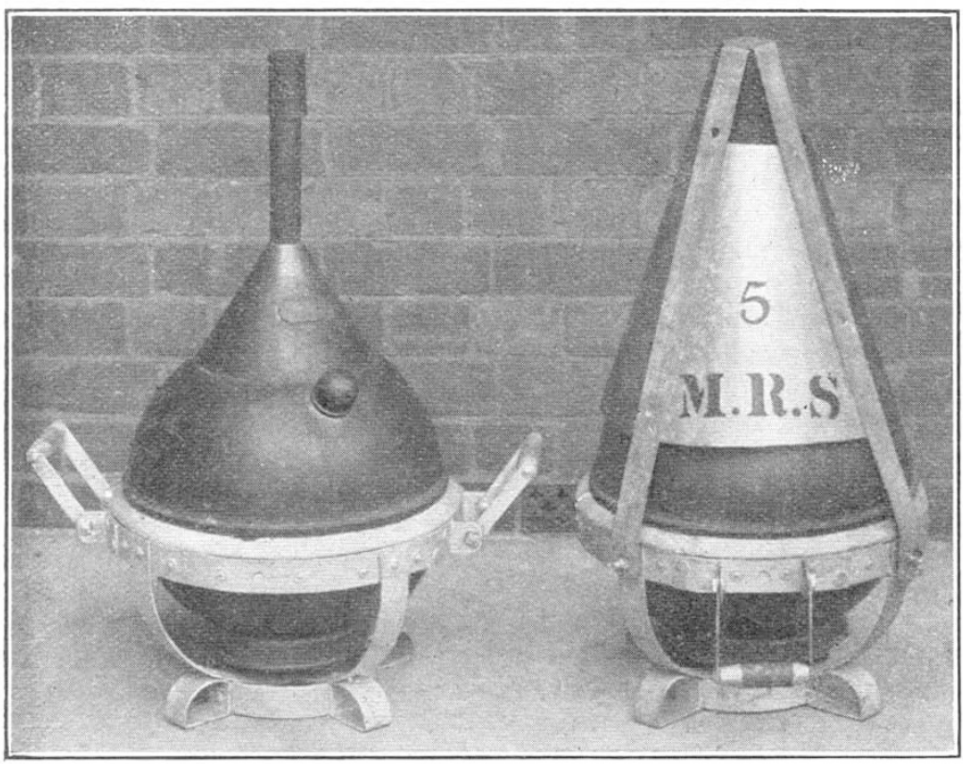

Fic. 2.- Steel cradles for the transport of containers. Reproduced, by permission of the Controller of H.M. Stationery Office, from the Third and Final Report of the Mine Rescue Apparatus Research Committee.

is its great simplicity in use. Compressed air appliances necessitate frequent adjustments, and occasional readings are required to be taken of the pressuregauge. These are not necessary with the aerophor type of apparatus, and in consequence the wearer is free to devote the whole of his attention to the work in hand. Another obvious advantage is the continuous reduction in the load to be carried when in use, due to the ebullition of the charge.

All existing forms of liquid-air apparatus, with the exception of that designed by Mr. G. A. Griffiths, have one defect in common, namely, the evaporation of the liquid air when the apparatus is not being used. The chief obstacles, however, that militate against the general adoption of liquid air for mine rescue work are connected not so much with the apparatus as with the manufacture, storage, and transport of the liquid. As pointed out in the Report, the manufacturing plant, which is costly, requires skilled attention, and has to be run at intervals to make good the loss by evaporation in the reserve of liquid kept in storage flasks. These flasks, although giving little trouble during normal use at the rescue stations, are so delicately constructed that they require very careful handling when being transported at the surface or underground.

The movements of the flasks during a rail or road journey must of necessity increase the rate of evaporation of the liquid air. Experiments, including those which have been carried out under the auspices of the Research Committee by Dr. Briggs and Mr. G. L. Brown, show that under ordinary conditions the loss by evaporation during transport is nearly twice the loss that occurs when the flasks are stationary. With the view of determining the most efficient means of supporting liquid air flasks during transport, two over good roads. The first container, which was placed on the floor of the car, lost $7 \mathrm{oz}$., whilst the second vessel, which was provided with trunnions carried in spring-mounted bearings, lost I4 oz. This unexpected result was due to the violent swinging of the vessel on its trunnions by the movement of the car, causing rapid ebullition of the air and frequent spurting of the liquid from the neck. As a result of this test the gimbal method of support has been entirely superseded by the simple steel cradle (Fig. 2), a form of stand which is giving remarkably efficient service. Storage flasks or containers form so essential a part of the equipment of liquid-air rescue stations that the Mines Rescue Research Committee is perfectly justified in devoting considerable space to them in its final Report.

The liquid air containers (Fig. 3) are similar in every respect to a "thermos" flask, except that they are made of brass or copper instead of glass, and that a small quantity of specially prepared charcoal is inserted in the vacuum space between the inner and outer vessels. Both vessels are constructed of two

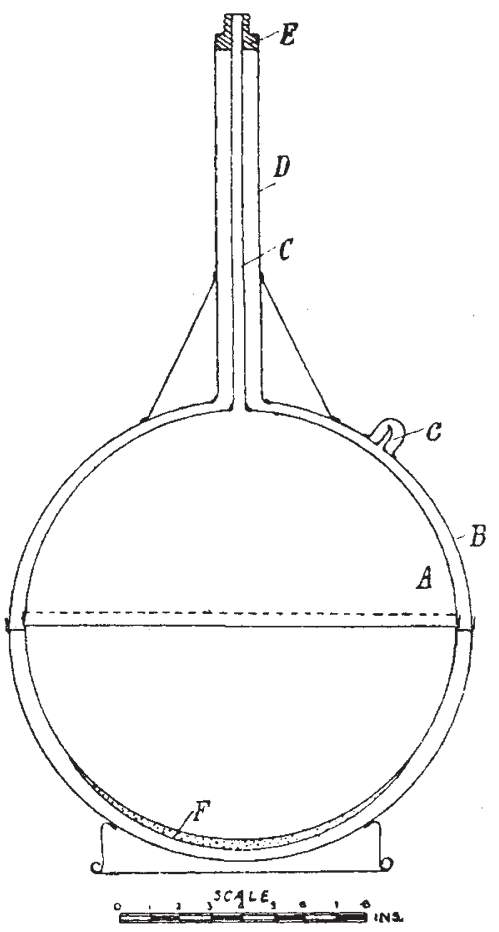

FIG. 3.-German 50-lb. liquid air container. Reproduced, by permission of the Controller of H.M. Stationery Office, from the Third and Final Report of the Mine Rescue Apparatus Research Committee.

hemispherical pressings, joined together by a soft solder, the two necks $\mathrm{C}$ and $\mathrm{D}$ being soldered to a plug $\mathrm{E}$ of solid drawn brass. A conical collar is fixed NO. 2867 , vOL. I I 4 ] 
around the base of the neck for additional support. The air from the vacuum space is extracted through a lead tube $\mathrm{G}$ of about $\frac{1}{4}$-in. bore. When evacuation is complete this lead is pressed flat, and is then burned off with a small Bunsen flame. The lead seal is protected by a cup-shaped cap filled with wax or bitumen. The surfaces of the globes which face each other across the vacuum space are very highly polished to reduce the transmission of heat by radiation to the liquid air.

The charcoal maintains the vacuum by absorbing the gas that leaks into the vacuous envelope through the porous metals. The remarkable absorptive power of charcoal at low temperatures, discovered by Sir James Dewar in 1905, has made possible the use of metallic vacuum flasks and is contributing most to the rapid expansion that is now taking place in the application of liquid air and oxygen for industrial and scientific purposes. Major Lambert found from experiments he carried out for the Oxygen Research Committee that British palm-nut charcoal was capable of abstracting the residual air from a vessel, which had previously been partially exhausted, to such an extent as to reduce the pressure from $0.0575 \mathrm{~mm}$. to $0.000005 \mathrm{~mm}$.

If it be assumed that the pressure-reduction factorinitial pressure/final pressure-is directly proportional to the amount of adsorbent used, then with the usual charge of $200 \mathrm{gm}$. of charcoal in a $50 \mathrm{lb}$. metal container, an initial pressure of $0 . \mathrm{I} \mathrm{mm}$. in the vacuum space will be reduced to a final pressure approaching $0.000002 \mathrm{~mm}$., at the temperature of liquid air. At this exceedingly low pressure the loss of heat by conduction across the vacuum space is negligible in comparison with the loss by radiation. For this reason it is not necessary to reduce the pressure in the envelope of a Dewar metal flask to the very low value required with the glass flask in the preliminary operation of pumping.

In order to determine the decay of the vacua of Dewar metal flasks, Dr. Briggs, a member of the Research Committee, has conducted a series of valuable experiments on 3 -litre flasks. The apparatus used enabled the outer wall of a vessel to be punctured, the pressure inside the envelope to be measured, and the puncture sealed without damaging the flask or destroying the vacuum. These experiments showed the average rate of decay of the vacuum to be about o.OI I mm. per month. This slight, though continuous, deterioration of the vacuum, due to leakage of air through the excessively minute pores of the metal, necessitates periodical re-evacuation of the envelope, an operation which is performed at certain English rescue stations by the simple hand-driven Geryk pump.

Very interesting particulars concerning the cost of making liquid air have been supplied to the Research Committee by the chief English liquid-air stations. At Station A the ro-years-old plant was run for 477 hours, during which time $8705 \mathrm{lb}$. of liquid air was produced with a power consumption of $0.78 \mathrm{k}$.w.h. per lb. The cost, including power, repairs, chemicals, oil and water, but not including depreciation, establishment charges and labour, was $14 \cdot 6 d$. per $1 b$. At Station B, $8837 \mathrm{lb}$. was made in 440 hours with a power consumption of I.I7 k.w.h. per lb. The cost, including power, repairs, chemicals, oil and water, was $2 \cdot 7 d$. per $1 b$. Depreciation on the plant at ro per cent. per year amounted to $4.3 d$., and establishment charges to $4.2 d$. per lb., giving a total cost of $\mathbf{I} \cdot 2 d$. per $\mathrm{lb}$.
Dr. S. H. C. Martin, F.R.S.

SIDNEY MARTIN, the second son of the late John $\checkmark$ Ewers Martin, was born in Jamaica in 1860 , and he entered University College, London, in 1876 , where he was a fellow-student and contemporary with Victor Horsley, Halliburton, and Frederick Mott. At this time many medical students at University College laid a sure foundation for their subsequent medical studies by following an extended course of instruction in biology, chemistry and physics, and Martin was one of these. He took his degree in science at the University of London in 1878 , being especially attracted to biology, largely owing to the stimulating influence of that inspiring teacher, Sir E. Ray Lankester. Afterwards, during his medical studies, he came under the influence of the late Sir John Burdon Sanderson, then Jodrell professor of physiology, who was not only a physiologist but also an experimental pathologist.

After graduating in medicine in 1883 , Martin began working, at the instigation of Burdon Sanderson, as an investigator in the Jodrell Laboratory, then under the control of Prof. Schäfer, who had succeeded Sanderson on the latter's appointment to the chair of physiology at Oxford. This period of the early 'eighties was one of great activity in physiology and pathology in Great Britain, and Martin devoted himself to what was then a new field, namely, the investigation of the chemical side of vital processes, and more

\section{t u a r y.}

especially to an inquiry into the nature of the so-called toxic proteids. At this time the number of workers in this branch of knowledge was extremely limited, especially in Great Britain, and Martin carried out a series of researches not only on abrine and ricine but also during a number of years on the wider question of the nature and mode of action of the toxic substances elaborated by the activity of micro-organisms in infective diseases, more especially diphtheria, tetanus and enteric fever. He developed this subject in a long series of investigations recorded in his Goulstonian and Croonian lectures delivered before the College of Physicians in 1892 and 1898 .

Although Martin's main work as an investigator was in the domain of chemical pathology, and he was one of the earliest workers in Great Britain on this subject, he was a recognised authority on pathology and pathological questions in the widest meaning of the terms. Thus he had an accurate and extensive knowledge of gross morbid anatomy and was professor of pathology at University College from I 895 to I907 and the author of a text-book on pathology. Further, all his work, both as an investigator and as a teacher of pathology, was directed to the furtherance of clinical medicine and towards increasing the power of the physician to cope with disease, and Martin was a practising physician throughout his career. He was a teacher at University College and Hospital throughout 